\title{
Hydrochloric Acid Corrosion Inhibition of Zn-Al-Cu Alloy by Methyl-Substituted Piperidines
}

\author{
S.S. Mahmoud* \\ Chemistry Department, University College of Girls for Arts, Science and Education, \\ Ain Shams University, Heliopolis, Cairo, Egypt
}

Received 4 June 2007; accepted 8 December 2007

\begin{abstract}
The corrosion behavior of $\mathrm{Zn}-\mathrm{Al}-\mathrm{Cu}$ alloy was investigated in $\mathrm{HCl}$ solution in absence and in presence of different concentrations of inhibitors. The techniques of measurements were: weight loss, linear polarization and galvanic static polarization. It was found that the corrosion rate of this alloy was higher than that of zinc or aluminum. The inhibitors used were: heterocyclic piperidine (PP), 2- methyl piperidine (2mp), 3methyl piperidine (3mp) and 4- methyl piperidine (4mp). These inhibitors are mixed type and their inhibition efficiency, I\%, increases according to the order: $2 \mathrm{mp}<3 \mathrm{mp}<$ $\mathrm{pp}<4 \mathrm{mp}$. The values of activation energy of corrosion were determined in absence and in presence of inhibitors. It was found that the presence of these inhibitors increases the values of activation energy. The adsorption of these inhibitors on the surface of the alloy follows Frumkin's isotherm.
\end{abstract}

Keywords: hydrochloric acid, corrosion inhibition, $\mathrm{Zn}-\mathrm{Al}-\mathrm{Cu}$ alloy, methyl-substituted piperidines.

\section{Introduction}

Zinc-aluminum alloys can be used for manufacturing fittings exposed to steam or seawater, gears, bushings and other components subject to friction. Also, Al-Zn, $\mathrm{Zn}-\mathrm{Al}$ and $\mathrm{Zn}$ are used as coatings for the protection of steel. These coatings were subjected to many investigations to test their corrosion resistance in different media [1-12]. These corrosive media included mainly seawater, and $\mathrm{NaCl}$ solutions. Little attention was paid to study the corrosion behavior of this $\mathrm{Zn}-\mathrm{Al}$, Al-Zn coatings in acid media. Corrosion inhibitors protect these alloys

\footnotetext{
* Corresponding author. E-mail address: drsohairr@hotmail.com.
} 
and coatings from the destructive effect of the acids. Most acid corrosion inhibitors are heterocyclic compounds containing nitrogen, sulphur or oxygen.

Inhibition appears to result from the adsorption of molecules and ions at the metallic surface. Adsorption depends on the chemical structure of the inhibitors, on the type of aggressive acid, and on the nature of the metal. Piperidine is a planar heterocyclic organic compound with amino nitrogen atom forming part of a six-member ring.

In the present work the corrosion behavior of $\mathrm{Zn}-\mathrm{Al}-\mathrm{Cu}$ alloy in $\mathrm{HCl}$ solutions was tested. Also, the inhibition of corrosion of this alloy in $\mathrm{HCl}$ using piperidine and its methyl-substituted derivatives was investigated. These compounds have the following molecular structure:<smiles>C1CCNCC1</smiles>

(pp)

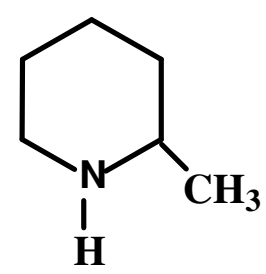

(2mp)<smiles>CC1CCCNC1</smiles>

(3mp)

piperidine

3-methyl piperidine<smiles>CC1CCNCC1</smiles>

(4mp)

4-methyl piperidine

These compounds were provided from Aldrich Chemical Co Ltd.

\section{Experimental}

The corrosion rate was determined by weight loss, linear polarization and Galvanostatic polarization measurements. Experiments were performed with the alloy having the composition: $96.34 \% \mathrm{Zn}, 2.8 \% \mathrm{Al}, 0.86 \% \mathrm{Cu}$. The samples used for weight loss measurements had the dimensions $3 \times 3 \times 0.4 \mathrm{~cm}$; for electrochemical measurements electrodes measuring $2 \times 1 \times 0.4 \mathrm{~cm}$ were used. For electrical connection, a stout copper wire lead was fixed at one end of the electrode by mechanical jamming. A platinum sheet of $1.5 \times 1.5 \mathrm{~cm}$ and a saturated calomel electrode (SCE) were used as an auxiliary and reference electrodes, respectively. The current values used in the electrochemical measurements were derived from a constant current unit $(2 \mu \mathrm{A}-200 \mathrm{~mA})$. The potential of working electrode relative to (SCE) was measured on digital millimeter (model 1008, Kyoritsu, Japan).

Prior to the weight loss and electrochemical measurements the samples and electrodes were polished with different emery papers up to $4 / 0$, washed the roughly with distilled water, rinsed in acetone and dried in air. The aggressive solutions were prepared by dilution of analytical grade $37 \% \mathrm{HCl}$ with doubly distilled water.

In weight loss measurements the alloy specimens were weighed before and after exposure time of five hours in the aggressive solution. From these weights the 
weight loss of the specimens was determined in grams and the corrosion rate, $R_{w}$, in $\left(\mathrm{g} / \mathrm{cm}^{2} / \mathrm{h}\right)$.

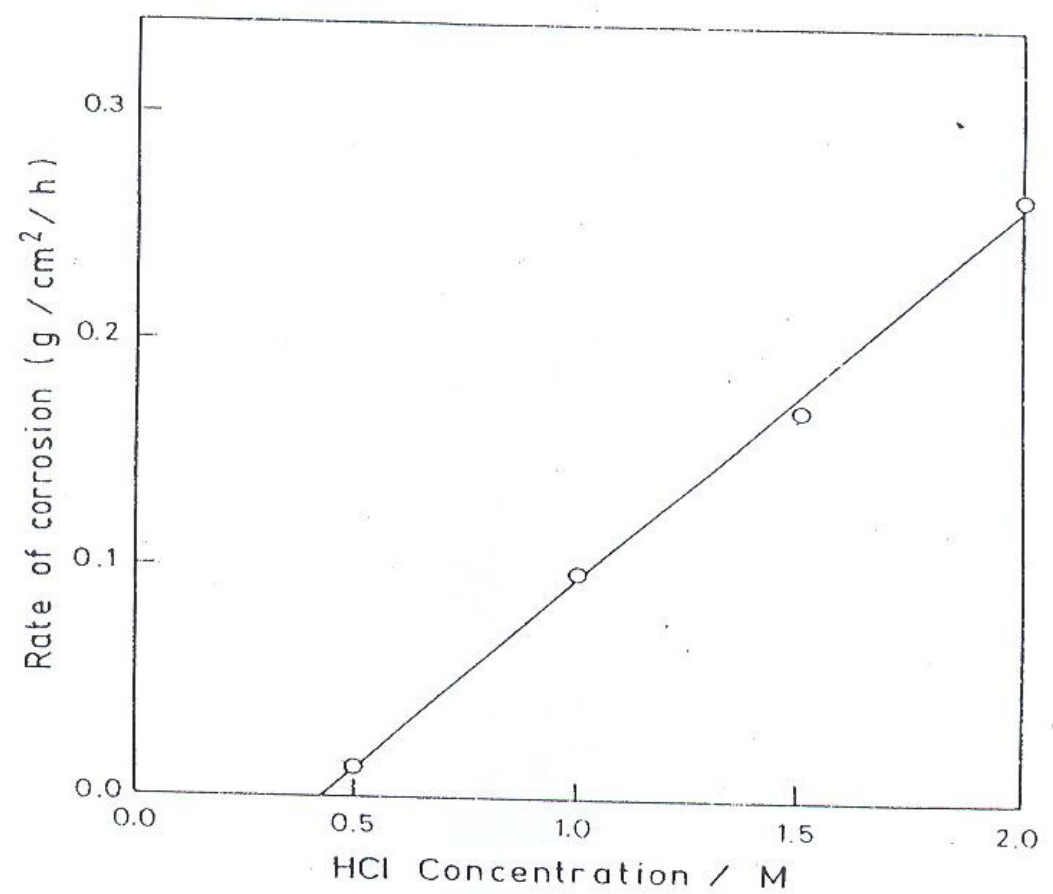

Figure 1. Plots of corrosion rate of the alloy versus the concentration of $\mathrm{HCl}$ at $25^{\circ} \mathrm{C}$.

\section{Results}

The corrosion behavior of the investigated alloy was tested in hydrochloric solution of different concentrations $(0.5,1,1.5,2 \mathrm{M})$ at the temperature of $25^{\circ} \mathrm{C}$ by weight loss measurements. The results of this investigation were depicted in Fig. 1 as corrosion rate $\left(\mathrm{g} / \mathrm{cm}^{2} / \mathrm{h}\right)$ versus the molarity of $\mathrm{HCl}$.These results indicate that the rate of corrosion of the investigated alloy greatly increases with the increase of acid concentration. The concentration of $0.5 \mathrm{M} \mathrm{HCl}$ solutions was chosen as an aggressive medium to evaluate the inhibitory effect of piperidine and its methyl-substituted derivatives on the corrosion of $\mathrm{Zn}-\mathrm{Al}-\mathrm{Cu}$ alloy.

In table 1 the results of weight-loss measurements were listed as corrosion rate, $\mathrm{R}_{\mathrm{w}}\left(\mathrm{g} / \mathrm{cm}^{2} / \mathrm{h}\right)$ of the alloy in $0.5 \mathrm{M} \mathrm{HCl}$ containing different concentrations of the investigated inhibitors. The values of inhibition efficiency, I\%, were calculated from the data of corrosion rate using the following equation:

$$
I \%=\left[1-\frac{R_{\text {inh }}}{R_{\text {free }}}\right] * 100
$$

where $R_{\text {free }}$ and $R_{\text {inh }}$ are the corrosion rates $\left(\mathrm{g} / \mathrm{cm}^{2} / \mathrm{h}\right)$ in the absence and in presence of inhibitors, respectively. The calculated values are listed in table 1 for the different concentrations of the investigated organic inhibitors. From these results it is clear that the value of $I \%$ increases with the increase of inhibitor 
concentration. Also, at a given concentration of the additive, the inhibition efficiency, I\%, increases according to the sequence: $2 \mathrm{mp}<3 \mathrm{mp}<\mathrm{pp}<4 \mathrm{mp}$.

Table 1. Data of weight loss measurements for the alloy in $0.5 \mathrm{M} \mathrm{HCl}$ solution in absence and in presence of different inhibitor concentrations at $25{ }^{\circ} \mathrm{C}$

\begin{tabular}{|c|c|c|c|c|c|c|c|c|}
\hline $\begin{array}{c}\text { inhibitor } \\
\text { concentration } \\
\text { (M) }\end{array}$ & $\begin{array}{c}\mathrm{pp} \\
\mathrm{R}_{\mathrm{w}} \\
\left(\mathrm{g} / \mathrm{cm}^{2} / \mathrm{h}\right)\end{array}$ & $\mathrm{I} \%$ & $\begin{array}{c}2 \mathrm{mp} \\
\mathrm{R}_{\mathrm{w}} \\
\left(\mathrm{g} / \mathrm{cm}^{2} / \mathrm{h}\right)\end{array}$ & $\mathrm{I} \%$ & $\begin{array}{c}3 \mathrm{mp} \\
\mathrm{R}_{\mathrm{w}} \\
\left(\mathrm{g} / \mathrm{cm}^{2} / \mathrm{h}\right)\end{array}$ & $\mathrm{I} \%$ & $\begin{array}{c}4 \mathrm{mp} \\
\mathrm{R}_{\mathrm{w}} \\
\left(\mathrm{g} / \mathrm{cm}^{2} / \mathrm{h}\right)\end{array}$ & $\mathrm{I} \%$ \\
\hline 0.00 & 0.0200 & 0.0 & 0.0200 & 0.0 & 0.0200 & 0.0 & 0.0200 & 0.0 \\
\hline $10^{-6}$ & 0.0140 & 30 & 0.0154 & 23 & 0.0150 & 25 & 0.0134 & 34 \\
\hline $10^{-5}$ & 0.0130 & 35 & 0.0140 & 30 & 0.0136 & 32 & 0.0122 & 39 \\
\hline $10^{-4}$ & 0.0070 & 65 & 0.0090 & 55 & 0.0080 & 60 & 0.0060 & 70 \\
\hline $10^{-3}$ & 0.0040 & 80 & 0.0060 & 70 & 0.0050 & 75 & 0.0030 & 85 \\
\hline $10^{-2}$ & 0.0016 & 92 & 0.0030 & 85 & 0.0024 & 88 & 0.0080 & 96 \\
\hline $10^{-1}$ & 0.0012 & 94 & 0.0026 & 87 & 0.0020 & 90 & 0.0004 & 98 \\
\hline
\end{tabular}

Fig. 2 represents the plots of linear polarization measurements for the investigated alloy in $0.5 \mathrm{M} \mathrm{HCl}$ in the absence and in presence of different concentrations of organic compound (pp). In this figure the potential, E, was plotted against the current density. Similar plots were obtained for the other three compounds ( $2 \mathrm{mp}, 3 \mathrm{mp}, 4 \mathrm{mp}$ ) but not shown. The values of polarization resistance, $R_{p}$, were deduced from the slopes $\left(\Delta E / \Delta i=R_{p}\right)$ of the straight lines of Fig. 2 and similar ones. The obtained values of $R_{p}$ were listed in table (2) for the different concentrations of the investigated organic compounds. The values of inhibition efficiency, I\%, were obtained from $\mathrm{R}_{\mathrm{p}}$ using the following equation:

$$
I \%=\left[1-\frac{\left(R_{p}\right)_{\text {free }}}{(R p)_{\text {inh }}}\right] * 100
$$

where $\left(R_{p}\right)_{\text {free }}$ and $\left(R_{p}\right)_{\text {inh }}$ are the polarization resistance in the absence and in presence of the inhibitor, respectively. The calculated values of I\% were listed in table 2 . These results indicate that the value of $I \%$ increases with the increasing the inhibitor concentration. Also, at a given inhibitor concentration, the value of I\% increases according to the sequence: $2 \mathrm{mp}<3 \mathrm{mp}<\mathrm{pp}<4 \mathrm{mp}$. These sequence is the same as that obtained by weight loss measurements. 


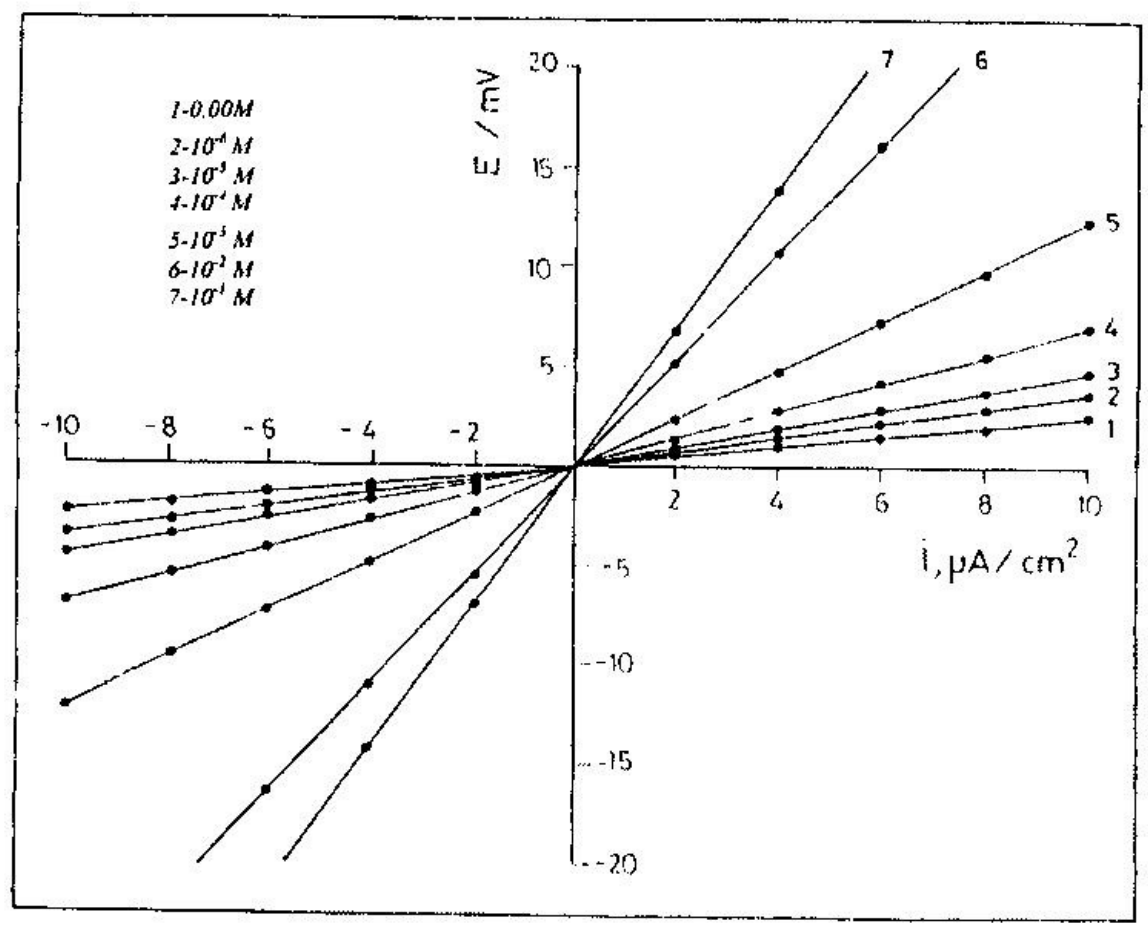

Figure 2. Linear polarization plots of $\mathrm{E}$ versus i for the alloy in $0.5 \mathrm{M} \mathrm{HCl}$ solution in the absence and presence of different concentrations of pp at $25^{\circ} \mathrm{C}$.

Table 2. Data of linear polarization measurements for the alloy in $0.5 \mathrm{M} \mathrm{HCl}$ solution in the absence and presence of different concentrations of inhibitors at $25{ }^{\circ} \mathrm{C}$. Values were obtained from polarization resistance.

\begin{tabular}{|c|c|c|c|c|c|c|c|c|}
\hline $\begin{array}{c}\text { inhibitor } \\
\text { concentration }\end{array}$ & $\mathrm{pp}$ & $\mathrm{R}_{\mathrm{p}}$ \\
$(\Omega)$ & $\mathrm{I} \%$ & $\begin{array}{c}2 \mathrm{mp} \\
(\Omega)\end{array}$ & $\mathrm{I} \%$ & $\begin{array}{c}\mathrm{R}_{\mathrm{p}} \\
(\Omega)\end{array}$ & $\mathrm{I} \%$ & $\begin{array}{c}\mathrm{R}_{\mathrm{p}} \\
(\Omega)\end{array}$ & $\mathrm{I} \%$ \\
\hline & 250.00 & 0.0 & 250.00 & 0.0 & 250.00 & 0.0 & 250.00 & 0.0 \\
0.00 & 367.64 & 32 & 320.50 & 22 & 338.00 & 26 & 384.50 & 35 \\
$10^{-6}$ & 390.63 & 36 & 352.00 & 29 & 373.10 & 33 & 417.00 & 40 \\
$10^{-5}$ & 735.00 & 66 & 543.50 & 54 & 641.00 & 61 & 862.00 & 71 \\
$10^{-4}$ & 1250.0 & 80 & 862.00 & 71 & 1000.0 & 75 & 1785.7 & 86 \\
$10^{-3}$ & 2778.0 & 91 & 1666.5 & 85 & 2272.5 & 89 & 5000.0 & 95 \\
$10^{-2}$ & 3571.5 & 93 & 2083.5 & 88 & 2778.0 & 91 & 12500 & 98 \\
$10^{-1}$ & & & & & & & \\
\hline
\end{tabular}




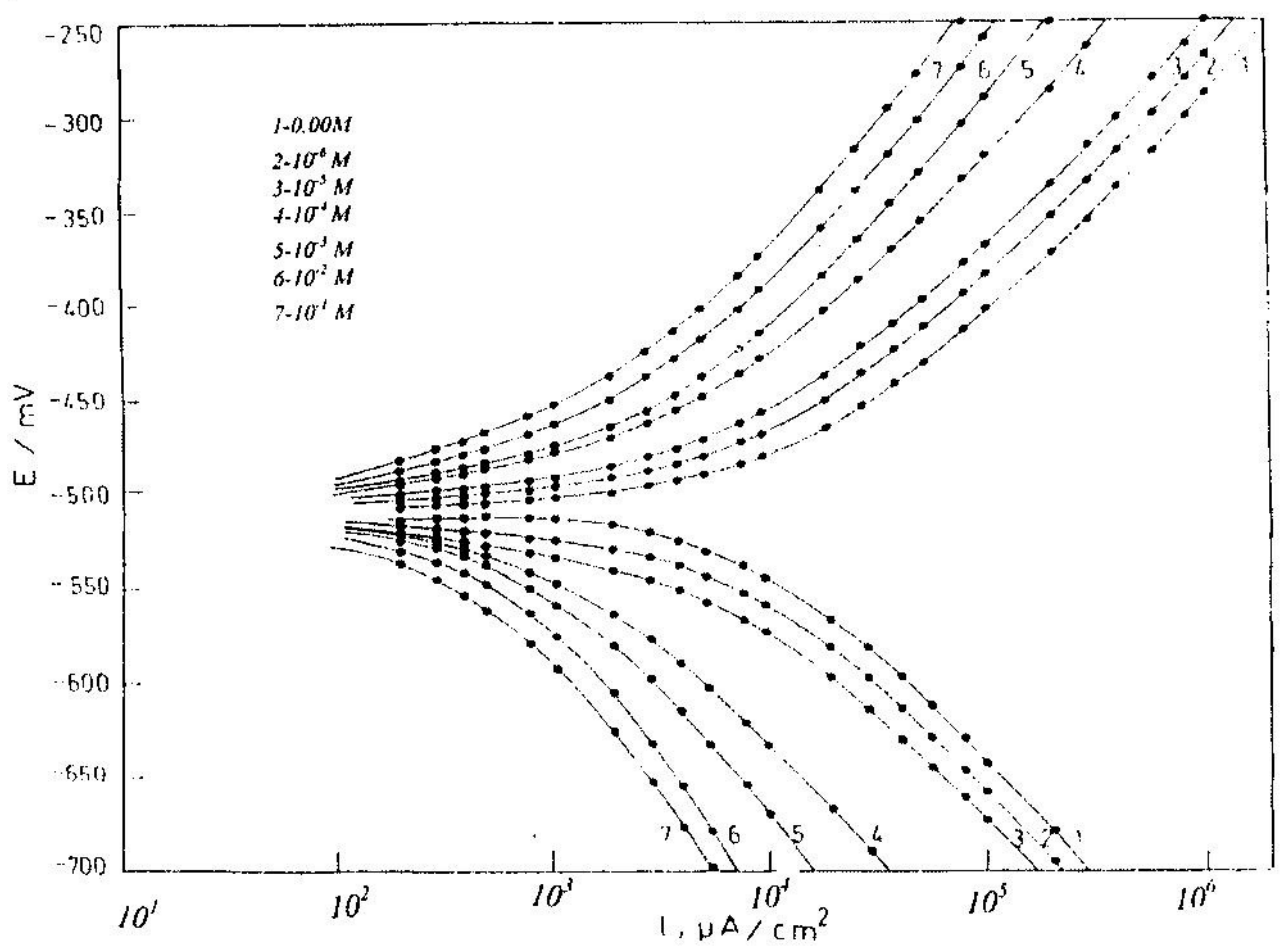

Figure 3. Galvanostatic polarization plots of $E$ versus $\log i$ for the alloy in $0.5 \mathrm{M} \mathrm{HCl}$ solution in the absence and presence of different concentrations of pp at $25^{\circ} \mathrm{C}$.

Fig. 3 represents the Galvanostatic cathodic and anodic polarization curves for the alloy in $0.5 \mathrm{M} \mathrm{HCl}$ in absence and in presence of different concentrations of organic compound (pp). Similar plots were obtained for the alloy in presence of different concentrations of the other three organic compounds, but not shown. The values of corrosion current density, $\mathrm{i}_{\text {corr }}$, were deduced from the polarization plots by extrapolation of Tafel's lines and listed in table 3 .

Table 3. Data of galvanostatic polarization measurements for the alloy in $0.5 \mathrm{M} \mathrm{HCl}$ solution in absence and in presence of different concentrations of inhibitors at $25^{\circ} \mathrm{C}$.

\begin{tabular}{|c|c|c|c|c|c|c|c|c|}
\hline $\begin{array}{c}\text { inhibitor } \\
\text { concentration } \\
\text { (M) }\end{array}$ & $\begin{array}{c}\mathrm{pp} \\
\mathrm{i}_{\text {corr }} \\
\mu \mathrm{A} / \mathrm{cm}^{2}\end{array}$ & $\mathrm{I} \%$ & $\begin{array}{c}2 \mathrm{mp} \\
\mathrm{i}_{\text {corr }} \\
\mu \mathrm{A} / \mathrm{cm}^{2}\end{array}$ & $\mathrm{I} \%$ & $\begin{array}{c}3 \mathrm{mp} \\
\mathrm{i}_{\text {corr }} \\
\mu \mathrm{A} / \mathrm{cm}^{2}\end{array}$ & $\mathrm{I} \%$ & $\begin{array}{c}4 \mathrm{mp} \\
\mathrm{i}_{\text {corr }} \\
\mu \mathrm{A} / \mathrm{cm}^{2}\end{array}$ & $\mathrm{I} \%$ \\
\hline $\begin{array}{l}0.00 \\
10^{-6} \\
10^{-5} \\
10^{-4} \\
10^{-3} \\
10^{-2} \\
10^{-1}\end{array}$ & $\begin{array}{c}1600 \\
1136 \\
1056 \\
544 \\
304 \\
144 \\
112\end{array}$ & $\begin{array}{l}0.0 \\
29 \\
34 \\
66 \\
81 \\
91 \\
93\end{array}$ & $\begin{array}{l}1600 \\
1248 \\
1152 \\
0736 \\
0480 \\
0256 \\
0224\end{array}$ & $\begin{array}{l}0.0 \\
22 \\
28 \\
54 \\
70 \\
84 \\
86\end{array}$ & $\begin{array}{c}1600 \\
1216 \\
1104 \\
640 \\
400 \\
176 \\
144\end{array}$ & $\begin{array}{l}0.0 \\
24 \\
31 \\
60 \\
75 \\
89 \\
91\end{array}$ & $\begin{array}{c}1600 \\
1056 \\
960 \\
480 \\
224 \\
48 \\
16\end{array}$ & $\begin{array}{l}0.0 \\
34 \\
40 \\
70 \\
86 \\
97 \\
99\end{array}$ \\
\hline
\end{tabular}


The values of inhibition efficiency, $\mathrm{I} \%$, were calculated from $\mathrm{i}_{\text {corr }}$ by using the equation:

$$
I \%=\left[1-\frac{\left(i_{\text {corr }}\right)_{\text {inh }}}{\left(i_{\text {corr }}\right)_{\text {free }}}\right] * 100
$$

where $\left(i_{\text {corr }}\right)_{\text {free }}$ and $\left(i_{\text {corr }}\right)_{\text {inh }}$ are the values of corrosion current density in absence and in presence of the inhibitor, respectively. The calculated values of $I \%$, are listed in table 3. These data indicate that the value of inhibition efficiency I\%, increases with the increase of the inhibitor concentration. Also, at a given inhibitor concentration, the value of $\mathrm{I} \%$ increases according to the sequence: $2 \mathrm{mp}$ $<3 \mathrm{mp}<\mathrm{pp}<4 \mathrm{mp}$; this sequence is the same as those obtained by weight-loss and linear polarization measurements.

\section{Discussion}

The results of Fig. 1 indicate that the corrosion rate of the investigated alloy greatly increases with the increase of $\mathrm{HCl}$ concentration: it increases from $0.02 \mathrm{~g}$ $\left./ \mathrm{cm}^{2} / \mathrm{h}\right)$ in $0.5 \mathrm{M} \mathrm{HCl}$ to $0.266\left(\mathrm{~g} / \mathrm{cm}^{2} / \mathrm{h}\right)$ in $2 \mathrm{M} \mathrm{HCl}$. This means that the rate of corrosion of the alloy increases about 13 times, when increasing the acid concentration 4 times. On the other hand, the corrosion rate of the alloy slightly increases in $\mathrm{HCl}$ solution of concentrations smaller than $0.5 \mathrm{M}$, where it has the values of $0.01,0.012$ and $0.015\left(\mathrm{~g} / \mathrm{cm}^{2} / \mathrm{h}\right)$ in $0.05,0.1$ and $0.25 \mathrm{M} \mathrm{HCl}$, respectively. Also, the corrosion rate of this alloy in $\mathrm{HCl}$ solutions is greatly higher than that of aluminium metal [13] or zinc metal [14-16].

Tanaka et al. [5], also found that the rate of cathodic reaction in $\mathrm{Zn}$-Al plating was faster than in Zn plating, state of which confirms the present studies. It was reported $[1,2,4]$ that the mechanism of corrosion was procceding in two discrete steps. The general attack of the surface involving corrosion predominantly the zinc phase of the alloy, hence creating pores into the alloy. After the zinc has been consumed by corrosion, aluminium is attaked within the matrix via chloride transport into these pores.

The results of this series of experiments indicate that in the presence of the investigated organic compounds there is a reduction in the corrosion rate of the alloy. In these media there is a competition between the active ions such as $\mathrm{Cl}^{-}$ ions and the inhibitor molecules for the adsorption on the metallic surface. The adsorbability of each of them greatly depends on their relative concentrations. This means that the inhibitive effect of organic molecules depends on the concentration of $\mathrm{Cl}^{-}$ions, which decreases with increasing ability of the inhibitor to form a protective layer on the metal surface. Other authors $[17,18]$ found that, at a constant, for each additive it is necessary to reach a particular concentration value before the additive to exert its inhibiting effect on the corrosion process; above this concentration, the inhibiting efficiency first increases with concentration, then it increases more slowly tending asymptotically to a limiting value. 
The corrosion inhibition study of the investigated compounds indicated that these compounds had a significant effect. This phenomenon was conferred by the presence of an electron donor group such as $\mathrm{N}$ in the piperidine structure. The presence of free electron pairs in $\mathrm{N}$ played the major rule in the adsorption of the organic compound on the metallic surface. The skeletal representation of the mode of adsorption of these compounds can be shown as follows:
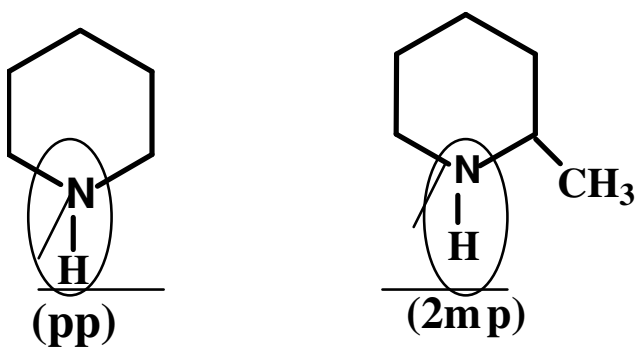

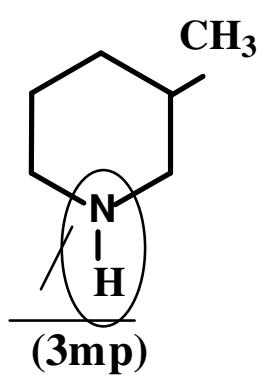

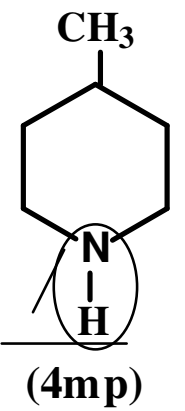

The relation between the surface coverage, $\theta$, (where $I \%=100 \theta$ ) and $\log C$ (where $\mathrm{C}$ is the molar concentration of the inhibitor) had the character of an $\mathrm{S}$ shaped adsorption isotherm, Fig. (4). This result showed that the investigated inhibitors were adsorbed on the alloy surface according to the Frumkin's isotherm [19]

$$
\theta(1-\theta)^{-1} \exp (-f C)=K C
$$

where $\mathrm{K}$ is the equilibrium constant of adsorption reaction, $\mathrm{f}$ is a function of adsorption energy, $\theta$ is the surface coverage and $\mathrm{C}$ is the molar inhibitor concentration. Also, the investigated inhibitors can be adsorbed on the alloy surface according to the Timken's isotherm, which can be represented by the equation:

$$
\theta=1 /-2 \mathrm{a}(\operatorname{lin} \mathrm{K})+1 /-2 \mathrm{a}(\operatorname{lin} \mathrm{C})
$$

where $\mathrm{a}$ is the molecular interaction parameter.

The obtained results of polarization measurements, Fig. 3, and similar ones, indicated that the investigated compounds behave as mixed inhibitors, i.e. both the cathodic and anodic polarization curves are affected by the presence of inhibitors in the corrosion medium [18,20,21]. In this study, it has been found that the magnitude of the displacement of the polarization curves appears to be dependent on the molecular structure of the inhibitor. Also, the cathodic and anodic current-potential curves gave rise to more or less parallel Tafel's lines, indicating that the hydrogen evolution and metal dissolution were activation controlled and the addition of organic inhibitors did not modify the mechanism of these processes [20,22]. The inhibiting action of such compounds occurs by the blocking of the electrode surface, thus decreasing the surface area available for the electrochemical reaction. 


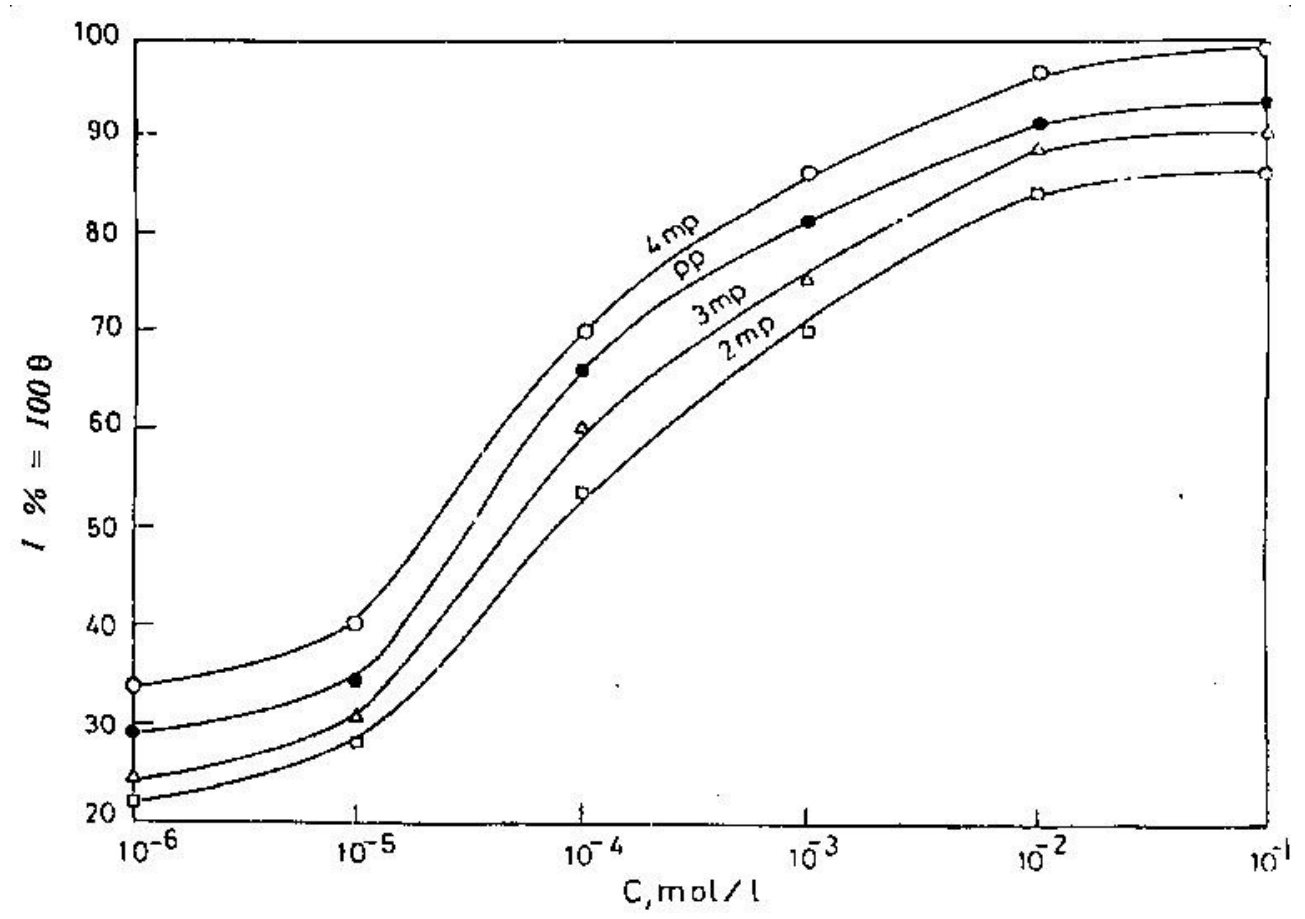

Figure 4. Adsorption isotherms of the inhibitors on the surface of the alloy.

To determine the activation energies of the corrosion process, the Galvanostatic polarization measurements were carried out at different temperatures of 25,35 , 45 and $55^{\circ} \mathrm{C}$ in $0.5 \mathrm{M} \mathrm{HCl}$ solutions in the absence and the presence of $10 \mathrm{M}$ of each of investigated inhibitors. The obtained results are depicted in Fig. 5 as Arrhenius plots of $1 / \mathrm{T}$ versus $\log \mathrm{i}_{\text {corr }}$ in $0.5 \mathrm{M} \mathrm{HCl}$ solution in the absence and in the presence of inhibitors. The values of apparent activation energy of corrosion, $\mathrm{E}_{\mathrm{a}}$ could be determined from equation (6),

$$
i_{\text {corr }}=K \exp \left[-\frac{E_{a}}{R T}\right]
$$

The calculated values of apparent activation energy, $E_{a}$, are: $47.7,76.4,84,64.1$ and $59.2 \mathrm{~kJ} / \mathrm{mole}$ in the absence and in the presence of the organic compounds $\mathrm{pp}, 4 \mathrm{mp}, 3 \mathrm{mp}$ and $2 \mathrm{mp}$, respectively.

Ideally, a corrosion inhibitor is a substance that increases the activation energy of the corrosion process. This is clear from the comparison of the values of $E_{a}$ in the absence and in the presence of investigated inhibitors. Since the presence of inhibitor causes a significant change in the value of the apparent activation energy, thus it indicates a change in the rate-determining step brought about the presence of inhibitor. The value of $E_{a}$ for the investigated inhibitors increases according to the order: $2 \mathrm{mp}<3 \mathrm{mp}<\mathrm{pp}<4 \mathrm{mp}$. This order is the same as that obtained for the inhibition efficiency, I \%, of these inhibitors, where the activation energy, $E_{a}$, increases with the increase of inhibition efficiency, $I \%$. 


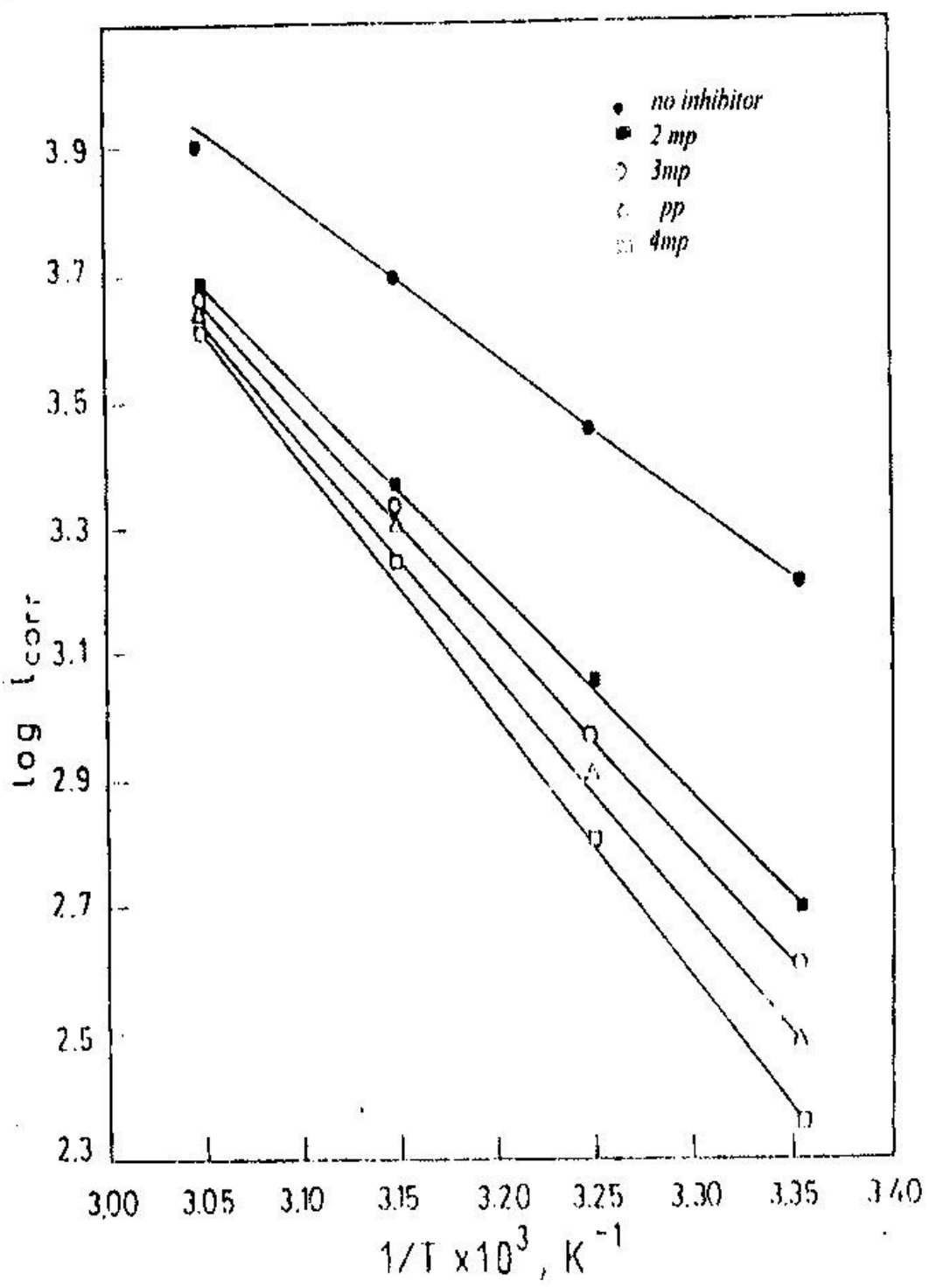

Figure 5. Arrhenius plots for the corrosion current densities of the alloy in the absence and presence of $10^{-3} \mathrm{M}$ of the inhibitors.

The possibility of correlating structural characteristics with the inhibition efficiency of organic substances is justified by the fact that the metal-inhibitor interactions are based on chemisorptions; it is possible to assume a bond of the Lewis acid-base type, generally with the inhibitor as the electron donor and the metal as the electron acceptor. The strength of this bond depends on the characteristics of both adsorbent and adsorbate. The obtained results show that the substitution of hydrogen in 4-postion of the piperidine ring by methyl group increases the inhibition efficiency of the organic compound (4mp). On the other hand the substitution in 2 and 3-positions decreases in the inhibition efficiency of the compounds ( $2 \mathrm{mp}, 3 \mathrm{mp})$. As above mentioned the inhibition efficiency of the investigated compounds increases according to the order: $2 \mathrm{mp}<3 \mathrm{mp}<\mathrm{pp}<$ $4 \mathrm{mp}$. It can be mentioned that the center of adsorption of the investigated organic compounds may be $\mathrm{N}$ atom. The introduction of methyl group in 4-position of heterocyclic ring increases the molecular size of the compound without any steric 
effect on the adsorption center (23). This state leads to the increase of inhibition efficiency of the compound $4 \mathrm{mp}$ that becomes better than the parent compound, pp. On the other hand, the introduction of methyl group in 2- and 3-positions gives rise to steric effect on the adsorption centers of the compounds ( $2 \mathrm{mp}$ and $3 \mathrm{mp}$ ) which in turn decreases the inhibition efficiency of the compounds and becomes smaller than the parent compound, pp. Also, it can be mentioned that the steric effect of 3-position is smaller than that of 2-position. This state leads to the above mentioned order of the inhibition efficiency of the investigated compounds.

\section{Conclusions}

1- The corrosion rate of the investigated alloy in $\mathrm{HCl}$ solutions is higher than those of $\mathrm{Al}$ or $\mathrm{Zn}$.

2- The corrosion rate of alloy greatly increases with the increase of $\mathrm{HCl}$ concentration.

3- Piperidine and its derivatives have high inhibition effect on the corrosion of the alloy in $0.5 \mathrm{M} \mathrm{HCl}$ solution.

4- The investigated inhibitors act as mixed inhibitors and don't change the hydrogen evolution mechanism and metal dissolution mechanism.

5- The inhibitory effect was the result of the interaction between the inhibitor molecule, via $\mathrm{N}$-atom, and the metallic surface that decreases the active surface.

6- The adsorption of investigated compounds on the alloy surface obeyed Frumkin's adsorption isotherm, and also Temkin's adsorption isotherm.

7- The values of inhibition efficiency of the compounds decreased with increasing the temperature and their addition led to an apparent increase in the activation corrosion energy.

\section{References}

1. A.K. Neufeld, I.S. Cole, Proc. Electrochem. Soc. 2000-25 (2001) 444- 452.

2. I.S. Cole, A.K. Neufeld, S.A. Furman, W.J. Miao, Proc. Electrochem. 200023 (2001) 284-294.

3. K. Haruhiko, Y. Hayami, A. Masani, Bosei Konri 45-3 (2001) 87- 91.

4. S.F.L. Mertens, E. Temmerman, Corros. Sci. 43-1 (2001) 69-84.

5. J. Tanaka, T. Tamura, T. Narita, Hyomen Gijutsu 51-12 (2000) 1224- 1228.

6. A.R. Moreira, Z. Panossian, J.R. Carvalho, I. Carlos da Silva, EBRATS $10^{\text {th }}$, Sao Paulo, Brazil, May 22-25 (2000) 617.

7. Y.- Li, Xu-Jun Wei; Fa-lun Ferg, Zhangguo Youse Jinsher Xuebao 11-2 (2001) 248-252.

8. L. Haufei, E.D. Jiashen, Mater- Perform. 40-5 (2001) 32-36.

9. J. Maki, S. Yamaguchi, T. Isaki, M.Kurosaki, Jpn Kokai Tokkyo Koho 316 (2001) 791.

10. J. Zhao, Proc. Corros. Prev. (2000) 612-617.

11. St. Gyurov, N. Guidikova, A. Ilinkina, Tekh. Misul. 33-3 (1996) 86-91 (Bulg). 
12. S. Nizoguchi, Y. Nishiki, Yosha Gijutsu 16-3 (1997) 34-40 (Jap).

13. G.A. EL-Mahdy and S.S. Mohmoud, Corros. Sci. 51 (1995) 436.

14. A.G. Gad-Allah, M.M. Hefny, S.A. Salih, M.S. El-Basiouny, Corrosion NACE 45 (1989) 574.

15. M.S. Abdel-Aal, Z.A. Ahmed, M.S. Hassan, J. Appl. Electrochem. 22 (1992) 1104.

16. S.G. Aziz, A.Y. Obaid, A.O. Alyoubi, A.A. Abdel-Fattah, Corros. Preven. Cont. 44 (1997) 179.

17. A. Frignani, G. Trabanelli, F. Zucchi, M. Zucchini, Proc. $5^{\text {th }}$ Europ. Symp. on Corros. Inhibitors, Ferrara, Italy, 1185 (1980).

18. E. Khamis, Corrosion 46-6 (1990) 476.

19. B. Hammouti, A. Aouniti, M. Taleb, M. Brighli, S. Kertit, Corros. Sci. 51 (1995) 411.

20. F. Bentiss, M. Traisnel, M. Lagrenee, Br. Corros. J. 35 (2000) 315.

21. B. Abd-EL Nabey, N. Khalil, A. Mohamed, Surface Technology 24 (1985) 383.

22. S. Kertit, B. Hammouti, Appl. Surf. Sci. 93 (1996) 59.

23. M. Hosseini, S.F.L. Mertens, M. Ghorbani, M.R. Arshad, Materials Chemistry and Physics 78 (2003) 800. 